\title{
SELF-CONTROL AND EMOTIONAL AND VERBAL AGGRSESION IN DATING RELATIONSHIPS: A DYADIC UNDERSTANDING
}

A thesis submitted

To Kent State University in partial Fulfillment of the requirements for the Degree of Master of Arts

\section{by}

Elizabeth Anne Baker

August, 2015 
Thesis written by Elizabeth Anne Baker

B.A., The University of Findlay, 2012

M.A., Kent State University, 2015

\section{Approved by}

$\begin{array}{ll}\text { Manfred H. M. van Dulmen, PhD } & \text { Advisor } \\ \text { Maria S. Zaragoza, PhD } & \text { Chair, Department of Psychological Sciences } \\ \text { James L. Blank, PhD } & \text { Dean, College of Arts and Science }\end{array}$




\section{TABLE OF CONTENTS}

LIST OF FIGURES $\ldots \ldots \ldots \ldots \ldots \ldots \ldots \ldots \ldots \ldots \ldots \ldots \ldots \ldots \ldots \ldots \ldots, \ldots \ldots \ldots$

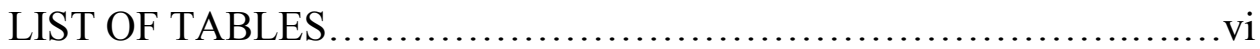

ACKNOWLEDGEMENTS $\ldots \ldots \ldots \ldots \ldots \ldots \ldots \ldots \ldots \ldots \ldots \ldots \ldots \ldots \ldots$ vii

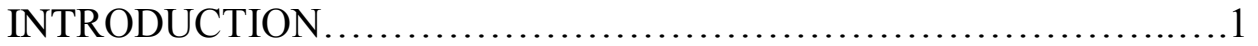

Self-Control and Dating Aggression............................2

Self-Control and EVA.......................................4

A Need for Dyadic Understanding..............................6

Contribution of Current Study ...................................

METHODS .................................................. 9

Participants.............................................9

Procedure................................................. 9

Measures................................................... 10

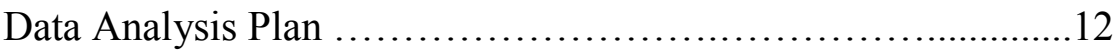

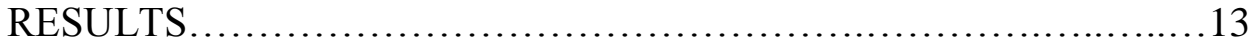

Does one's own self-control predict EVA?........................14

Does partner self-control predict EVA?...................... 14

DISCUSSION ............................................... 17

Self-control associated with EVA............................17

Both self and partner self-control associated with EVA..........18

Hypotheses' extension across methodologies..................20

Does self-control differentially predict EVA perpetration versus

EVA victimization?..........................................................22

Implications for Interventions .............................23

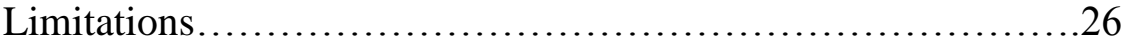

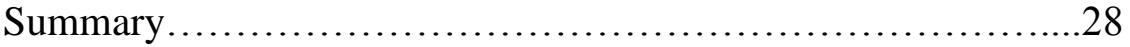

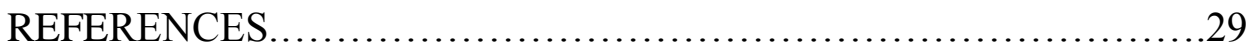


APPENDICES ................................................... 36 
List of Figures

Figure 1. Actor-Partner Interdependence Model of Self-Control Predicting Observed, Perpetration, and Victimization of EVA......................................................... 16 
List of Tables

Table 1. Observed EVA, Perpetration of EVA, Victimization of EVA, and Self-Control 


\section{Acknowledgments}

I am so incredibly grateful for everyone who has helped me throughout this process. I would like to take this opportunity to first thank my advisor, Dr. Manfred van Dulmen, for mentoring me throughout this experience. I would also like to thank the members of my committee for their help with this project: Dr. John Dunlosky, Dr. Judith Gere, and Dr. Christopher Flessner. I am extremely grateful for Dr. Evelyn Buday, who sparked my initial interest in research. I also would like to express gratitude to my labmates who have supported me throughout this process. Thank you, Mom, for your endless encouragement. Thank you, Dad, for giving me inspiration. Thank you, David, for your sense of humor. I am also extremely grateful for the entire community at One Love Yoga for teaching me to take the self-compassion, courage, and perseverance that I learned on the mat and bring it to my work. And thank you Greg for teaching me that it is not only possible, but that it is preferable, to enjoy life in times of stress. 


\section{Introduction}

Aggression in intimate relationships is a prevalent and important issue (see Capaldi, Knoble, Shortt, \& Kim, 2012 for review), with reports from the United States finding that over one in three women and one in four men experience physical aggression, sexual aggression, and/or stalking by an intimate partner at some point in their lifetime (Center for Injury Prevention and Control, 2010a). Yet, even more prevalent is emotional and verbal aggression (EVA), with nearly half of all men and women in the United States experiencing EVA victimization in their lifetime (Center for Injury Prevention and Control, 2010a). Although there are multiple definitions of EVA used in the literature, here we conceptualize EVA as the intention to negatively affect someone's emotional well-being through the use of verbal comments (i.e., insults; Wolfe et al., 2001).

In addition to being the subtype of aggression that occurs most often in romantic relationships, EVA has serious implications for a number of negative mental and physical health outcomes, such as depression and anxiety (Lawrence, Yoon, Langer, \& Ro, 2009; Taft et al., 2006), poorer physical health symptoms (Taft et. al, 2006), and cognitive impairment (Straight, Harper, \& Arias, 2003). Additionally, EVA is predictive of physical aggression (Murphy \& O’Leary, 1989; Baker \& Stith, 2008). Due to the fact that EVA is the most commonly experienced form of aggression in romantic relationships, and that it is predictive of a number of negative outcomes, our research focuses specifically on this subtype. Given that the onset of aggression perpetrated against 
a romantic partner tends to occur before the age of 24 years (Centers for Disease Control and Prevention, 2010b), young adults offer a unique opportunity to explore and intervene on risk factors for EVA perpetrated by dating partners, and are therefore the age-group we focus on in our study.

\section{Self-Control and Dating Aggression}

While risk factors for dating aggression are multi-faceted and include both individual and contextual risk factors (see for an overview Capaldi et al., 2012), recent work hones in on one's ability to control one's own actions as a risk factor for aggression among intimate partners. This ability to "regulate and override impulses and urges, including thoughts, desires, and behaviors" (Watkins, DeLillo, Hoffman, \& Templi, 2015 , p. 2) refers to one's self-control.

Theoretical work guided by Finkel and colleagues (Finkel, 2007; DeWall, Finkel, \& Denson, 2011; Denson, DeWall, \& Finkel, 2012; Finkel, 2013) has been instrumental in advancing our understanding of the role that self-control plays in dating aggression. Finkel's $I^{3}$ theory suggests that there are three components involved in predicting aggressive behavior: instigation, impellance, and inhibition (Finkel, 2013; Finkel, 2007). Instigation refers to events that may provoke aggression (i.e., provocation during conflict with a romantic partner), impellance refers to individual or situational risk factors that may increase the urge to aggress (i.e., trait aggressiveness), and inhibition refers to the ability to override these impelling and instigating forces (i.e., self-control). Our study focuses on the inhibition portion of the $\mathrm{I}^{3}$ theory. In support of the $\mathrm{I}^{3}$ theory of intimate 
partner violence, past research suggests that many individuals do, in fact, experience violent impelling impulses when arguing with their romantic partner (Finkel, DeWall, Slotter, Oaten, \& Foshee, 2009). However, this same research suggests that vast majority of individuals do not actually act on the impelling forces. In order to investigate factors that differentiate those who act on aggressive impulses from those who do not, selfcontrol (the inhibiting factor in the $\mathrm{I}^{3}$ theory) becomes of central importance.

Finkel and colleagues' (2007) research examines several potential factors of selfcontrol that influence the tendency to become aggressive, including cognitive processing time (time taken that is used to decide to respond to something), self-regulatory strength, and dispositional self-control in relation to measures of physical aggression towards a romantic partner. Not surprisingly, limited processing time and depletions in selfregulatory strength are associated with a greater tendency toward aggression. Specifically, when individuals are allowed to immediately respond to an insulting and jealousy-provoking hypothetical situation, as opposed to having to wait ten seconds, their coded responses contain more tendencies toward physical aggression. Additionally, those who experience both self-regulatory depletion and provocation from their partner are more likely to make their partners hold uncomfortable yoga poses for a longer period of time (an analog measure of physical aggression). In addition, individuals with high dispositional self-control report fewer acts of perpetration of physical aggression towards individuals they had dated in the past year.

Additional support for the association between self-control and aggression comes from neurobiological research. Recent reviews on this body of research discuss the 
mechanisms of self-control and aggression, stating that the same regions of the prefrontal cortex that control anger and aggressive urges broadly support self-regulation.

Accordingly, individuals with abnormalities in these regions display aggressive behavior (see DeWall et. al, 2011; Denson et. al, 2012 for review). Furthermore, low levels of selfcontrol are associated with relationship aggression perpetration in male batterers with head injuries (e.g., Warnken, Rosenbaum, Fletcher, Hoge, \& Adelman, 1994; Marsh \& Martinovich, 2006) and executive dysfunction (e.g., Marsh \& Martinovich, 2006; Walling, Meehan, Marshall, Holtzworth-Munroe \& Taft, 2012).

\section{Self-Control and EVA}

Although previous research examining self-control and dating aggression focuses mainly on physical aggression, we hypothesize that self-control is also a key factor in understanding the subtype of EVA as well. The main argument for this hypothesis is based on previous research (Finkel \& Campbell, 2001) examining the link between selfcontrol and accommodation. Accommodation refers to the ability to inhibit a potentially destructive response and replace it with a constructive one (Finkel \& Campbell, 2001). During conversations between romantic partners, especially conversations that involve discussing a major problem area in relationships, there are many potential instances during which one partner may, intentionally or unintentionally, say something to provoke their partner. The other partner can then respond with a destructive or constructive response. In the case that a destructive response occurs, portions of that destructive response may include EVA. Finkel and Campbell's study (2001) found that both higher 
trait self-control, as well as higher in-the-moment self-control, are beneficial for accommodation in relationships. It follows, then, that the benefits that self-control provides in allowing an individual to replace a destructive response with a constructive response may similarly lead us to expect that higher self-control would be predictive of less EVA.

Relatedly, some research (also guided by the $\mathrm{I}^{3}$ theory) investigates the circumstances that predict aggressive verbalizations. Specifically, work by Maladano, DiLillo, \& Hoffman (2015) examines how various emotion regulation strategies (cognitive reappraisal and suppression) affect aggressive verbalizations.

In Maladano and colleagues' (2015) study, participants (both perpetrators and non-perpetrators of IPA) listened to different emotionally evocative dating scenarios and were either given no instruction, told to use cognitive reappraisal, or to suppress their emotions. Afterwards they expressed their thoughts and feelings regarding the scenarios. Their verbalized responses were coded into an aggregate variable (made up of verbal aggression, physical aggression, and belligerence). Perpetrators in the cognitive reappraisal condition showed fewer aggressive verbalizations, and perpetrators in the suppression condition showed more aggressive verbalizations compared to those who were not perpetrators.

This work by Maladano and colleagues provides us with some evidence for who is more likely to verbally aggress, and under what conditions, as guided by the $\mathrm{I}^{3}$ theory. However, this work used individual participants that responded to hypothetical scenarios. Therefore, it does not tell us anything about the use of EVA by both partners during an 
actual conflict. As stated by the authors, "lab-based studies are needed to examine emotion regulatory processes as they play out during actual couple conflict" (Maladano et al., 2015, p. 11). In order to fully understand the association between self-control and EVA, we need to consider both partners using a dyadic approach and to use observational methodology to investigate EVA during actual conflict between couples. The current study aims to fill this gap in the literature.

\section{A Need for Dyadic Understanding}

Past empirical research and theory supports the association between self-control and dating aggression. However, much of this research investigates dating aggression at the level of the individual. This is problematic because dating aggression does not occur in isolation. Rather, it is bidirectional in nature, with each partner mutually influencing the other. Research on EVA in particular consistently demonstrates that EVA is mutual phenomenon, being perpetrated by both males and females (see O’Leary \& Slep, 2012 for review).

The dynamic developmental systems perspective (e.g. Capaldi, Short, \& Kim, 2005) is one theory that accommodates both self and partner characteristics as they impact outcomes of dating aggression at the dyadic level. More specifically, the dynamic developmental systems perspective emphasizes the role of characteristics of both individuals in a relationship in understanding relationship processes including the development and resolution of conflictual situations (e.g., Capaldi et al., 2005; Capaldi \& Gorman-Smith, 2003; Capaldi \& Kim, 2007; Capladi, Kim, \& Shortt, 2004; Capaldi, 
Shortt, \& Crosby, 2003). It conceptualizes dating aggression to be bidirectional, with both partners influencing their own, as well as their partner's, outcomes. The focus of this theory, then, is on how partners influence themselves, each other, as well as the nature of the conflict as a whole. This theoretical support, combined with the previously mentioned empirical evidence, lends ample support for the study of both individuals in the dyad. Furthermore, dating aggression intervention efforts are most effective when characteristics of both partners are being considered (O'Leary \& Slep, 2012). Therefore it is necessary to move towards a dyadic understanding of dating aggression by using the best practices in methodology.

Indeed, recent research is beginning to move towards considering the bidirectional effects of dating aggression. For example, a recent study examines selfcontrol depletion predicting aggression by collecting and analyzing data from both partners (Watkins et al., 2015). Watkins and colleagues' research provide evidence for the importance of self-control in intimate partner aggression, and importantly, for the dyadic processes behind it. Their results suggest that partners both "recognize and respond to each other's negative affect and depletion in ways that influence aggression" (Watkins et al., 2015, p. 12). It is therefore necessary to include not only components of the $\mathrm{I}^{3}$ theory when examining self-control and dating aggression, but also to incorporate the dynamic developmental systems perspective to uncover the dyadic effects of such an association.

Although Watkins' research provides empirical evidence for the importance of examining self-control and aggression within a dyadic framework, it does not tell us how 
EVA functions during an actual conflict. Their study measures aggression with the use of white noise blasts following a conflict. While their findings are extremely important in understanding dating aggression, it does not tell us anything about how self-control and EVA are associated during an actual conflict between couples.

\section{Contribution of Current Study}

The current study aims to examine the association between self-control and EVA (as guided by the inhibiting facet of the $\mathrm{I}^{3}$ theory) within a dyadic framework (as guided by the developmental systems perspective) during couple conflict. Guided by the $\mathrm{I}^{3}$ theory, we hypothesized that one's own self-control impacts one's own perpetration of EVA. Furthermore, as guided by dynamic developmental systems perspective, we hypothesized that partner self-control also impacts EVA. Specifically, we hypothesized that there is a negative relationship between self-control and perpetrating EVA for both one's self and for one's dating partner. Additionally, we wanted to examine if hypotheses would extend across different methodologies (observational, self-report). Finally we wanted to explore the role of victimization in the association between self-control and EVA. Although perpetration and victimization of dating aggression are highly correlated, it is possible that these constructs have different predictors and outcomes. Therefore, we have included a measure of victimization to examine how the association between selfcontrol and victimization of EVA may differ from the association between self-control and perpetration of EVA 


\section{Methods}

\section{Participants}

The current investigation utilized data from the Transitions into Adulthood and Romantic Relationships Study (van Dulmen, Mata, \& Klipfel, 2012). Participants included 120 dating couples from a large Midwestern university. One member of the couple was recruited through an undergraduate research pool in order to fulfill a research requirement for their undergraduate psychology course. To be eligible for the study, the participant needed to be between the ages of 18 and 25 and had to have been involved in a heterosexual romantic relationship for at least four months. Homosexual couples $(n=4)$ and couples that were not observationally coded due to technical difficulties $(n=3)$ were excluded from the current study. The remaining sample consisted of 113 couples $\left(M_{\text {age }}=19.78,88 \%\right.$ Caucasian, 52\% dating for longer than one year). The participant received course credit for the initial assessment, and their romantic partners received monetary compensation of $\$ 25$. The Kent State Institutional Review Board approved the study (IRB \# 07-226).

\section{Procedure}

As part of a larger study, all participants completed a battery of assessments to assess continuity and change in romantic relationships. Included in this study were 
measures of self-control, self-reported EVA in dating relationships, issues in the current romantic relationship, and a general demographic questionnaire. After completing the surveys, couples completed the revised Markman-Cox Couple Interaction Observation Procedure (Cox, 1991). During this part of the assessment, couples reviewed a list of possible romantic relationship problems they had previously filled out individually. The couples then had four minutes to agree on the biggest problem area in their relationship. They then had ten minutes to come up with a compromise or solution to the problem. Following that portion, the couples were given four minutes to decide what they agree upon most in their relationships from the same list. Finally, the couples were given ten minutes to plan a hypothetical all-expenses paid three day vacation to the destination of their choice. This interaction was video recorded for subsequent observational coding of EVA.

\section{Measures}

Self-control. Grasmick et al.’s Low Self-Control Scale (Grasmick, Tittle, Bursik, \& Arnekely, 1993) was used to assess self-control. This is a 24 item scale that includes questions such as "I often act on the spur of the moment without stopping to think" and "I like to test myself every now and then by doing something a little risky". This scale has been shown to be both reliable and valid in the past, and demonstrating good reliability in our study $(\alpha=.83)$. Items are assessed on a 4-point likert scale, with higher scores reflecting less self-control. However, for ease of interpretation, we reverse scored this 
measure so that higher scores reflect higher self-control. A total self-control score was derived by averaging all the items.

Self-reported EVA perpetration and victimization. The Conflict in Adolescent Dating Relationships Inventory CADRI Inventory (Wolfe et al., 2001) is a 70 item scale with six subscales that assess threatening behavior, physical abuse, sexual abuse, relational aggression, emotional and verbal abuse, and positive strategies within the past year. Four items were drawn from the ten item emotional and verbal abuse scale in order to match the observationally coded constructs discussed below $(\alpha=.82)$. Sample items include "I said things just to make him/her angry" and "I insulted him/her with putdowns" (perpetration) and "He/she said things just to make me angry" and "He/she insulted me with put-downs" (victimization). Items are assessed on a four point likert scale, with greater numbers indicating higher frequency $(1=$ never, $2=$ seldom $3=$ sometimes, 4 = often).

Observationally assessed perpetration of EVA. A coding scheme adapted from the emotional and verbal abuse subscale of the CADRI was used to assess observed EVA (van Dulmen et al., 2012; interrater reliability r's ranging from .59 to .81) during the observational task. Four items were excluded because they were unlikely to occur during the assessment or because of their subjective nature (threatening to end the relationship, ridiculing one's partner in front of others, keeping track of who one's partner was with, and keeping track of where one's partner was) and two were excluded due to low variability (doing something to make one's partner jealous, accusing one's partner of flirting). The final coding scheme included the following four constructs: blaming one's 
partner for a problem, insulting one's partner with put-downs, saying something to make one's partner angry, bringing up something bad that one's partner did in the past. The frequency of each behavior was rated on a four point scale, with higher scores indicating a greater frequency of occurrence $(1=$ never, $2=$ seldom $3=$ sometimes, $4=$ often $)$. Internal consistence was adequate for both females $(\alpha=.61)$ and males $(\alpha=.62)$.

\section{Data Analysis Plan}

Given the nature of the relationship between romantic partners, it is necessary to use a statistical technique that takes into account the interdependence of dyadic couples. Furthermore, dyadic data violates the independence assumption of most statistical techniques (e.g. linear regression). Kenny's APIM framework is able to look at both the way in which one's own characteristics affects their own outcome (actor effects), as well as the way one's own characteristics affects their partner's outcome (partner effects; Kenny, 1996; Kenny, Kashy, \& Cook, 2006). Furthermore, the APIM models the nonindependence of the dyadic data. As recommended by Kenny and colleagues, we chose to report the unstandardized coefficients when using the APIM technique (Kenny et. al, 2006, p.179). 


\section{Results}

Significant bivariate correlations (Table 1) ranged from $r=-0.35$ (female selfcontrol and female observed EVA; male self-control and male victimization) to $r=0.91$ (female victimization and female perpetration). There were moderate associations between male and female perpetration of EVA $(r=0.44, p<.001)$, male and female victimization of EVA $(r=0.55, p<.001)$, and male and female observed EVA $(r=0.52$, $p<.001)$. Male self-control was not significantly associated with female self-control.

Table 1

Observed EVA, Perpetration of EVA, Victimization of EVA, and Self-Control $(N=113)$

\begin{tabular}{|c|c|c|c|c|c|c|c|c|}
\hline & 1 & 2 & 3 & 4 & 5 & 6 & 7 & 8 \\
\hline $\begin{array}{l}\text { 1. Female Observed } \\
\text { EVA }\end{array}$ & - & & & & & & & \\
\hline 2. Male Observed EVA & $0.52 * * *$ & - & & & & & & \\
\hline 3. Female Perpetration & $0.25 * *$ & $0.26 * *$ & - & & & & & \\
\hline 4. Male Perpetration & $0.31 * * *$ & $0.30 * *$ & $\begin{array}{c}0.44 * * \\
*\end{array}$ & - & & & & \\
\hline 5. Male Victimization & $0.37 * * *$ & $0.25 * *$ & $\begin{array}{c}0.54 * * \\
*\end{array}$ & $0.90 * * *$ & - & & & \\
\hline $\begin{array}{l}\text { 6. Female } \\
\text { Victimization }\end{array}$ & $0.29 * *$ & $0.29 * *$ & $\begin{array}{c}0.91 * * \\
*\end{array}$ & $0.44 * * *$ & $0.55 * * *$ & - & & \\
\hline 7 Female Self-Control & $-0.35 * * *$ & $-0.34 * * *$ & $-0.22 *$ & -0.07 & -0.08 & $-0.17 *$ & - & \\
\hline 8 Male Self-Control & -0.11 & -0.05 & $-0.22 *$ & $-0.23^{*}$ & $-0.35 * * *$ & $-0.25 * *$ & -0.01 & - \\
\hline$M$ & 2.08 & 1.92 & 2.02 & 1.91 & 1.92 & 1.95 & 2.90 & 2.85 \\
\hline$S D$ & 0.57 & 0.63 & 0.73 & 0.79 & 0.81 & 0.72 & 0.35 & 0.38 \\
\hline$\alpha$ & 0.61 & 0.62 & 0.81 & 0.83 & 0.82 & 0.80 & 0.83 & 0.81 \\
\hline
\end{tabular}

$* p<.05 . * * p<.01 . * * * p<.001$. 


\section{Does one's own self-control predict EVA?}

Our hypothesis that one's own self-control would be negatively associated with EVA was partially confirmed (Figure 1). For females, self-control predicted observed EVA $(b=-0.57, p<.001)$ and perpetration $(b=-0.44, p<.05)$, but not victimization $(b=$ $-0.33, p>.05)$. For males, self-control negatively predicted perpetration $(b=-0.47, p<$. $05)$ and victimization $(b=-0.74, p<.001)$, but not observationally assessed EVA ( $b=$ $0.08, p>.05)$.

Testing for gender differences, analyses including equality constraints suggested that males and females did significantly differ for observationally assessed EVA $\left(\Delta \chi^{2}=\right.$ $5.66, p<.05)$, but not for perpetration $\left(\Delta \chi^{2}=0.02, p>.05\right)$ or victimization $\left(\Delta \chi^{2}=2.41, p\right.$ $>$.05). Together, these findings suggest that the association between one's own selfcontrol and observationally assessed EVA was stronger for females $(b=-0.57)$ compared to males $(b=-0.08)$.

\section{Does partner self-control predict EVA?}

Our hypothesis that partner self-control would be associated with EVA was partially confirmed (Figure 1). Females' self-control negatively predicted their partners' observed EVA $(b=-0.60, \mathrm{p}<.001)$, but not perpetration $(b=-0.15, p>.05)$ or victimization $(b=-0.17, p>.05)$. Males' self-control negatively predicted their partners' perpetration $(b$ $=-0.42, p<.05)$ and victimization $(b=-0.47, p<.01)$, but not observed EVA $(b=-0.16$, $p>.05)$. 
Testing for gender differences, analyses suggested that males and females did significantly differ from one another for observed EVA $\left(\Delta \chi^{2}=4.50, p<.05\right)$, but not for perpetration $\left(\Delta \chi^{2}=1.05, p>.05\right)$ or victimization $\left(\Delta \chi^{2}=1.22, p>.05\right)$. Together, these findings suggest that self-control is more strongly associated with observationally assessed partner EVA for females $(b=-0.60)$ compared to males $(b=-0.16)$. 


\section{Figure 1.}

Actor-Partner Interdependence Model of Self-Control Predicting Observed, Perpetration, and Victimization of EVA $(\mathrm{N}=113)$

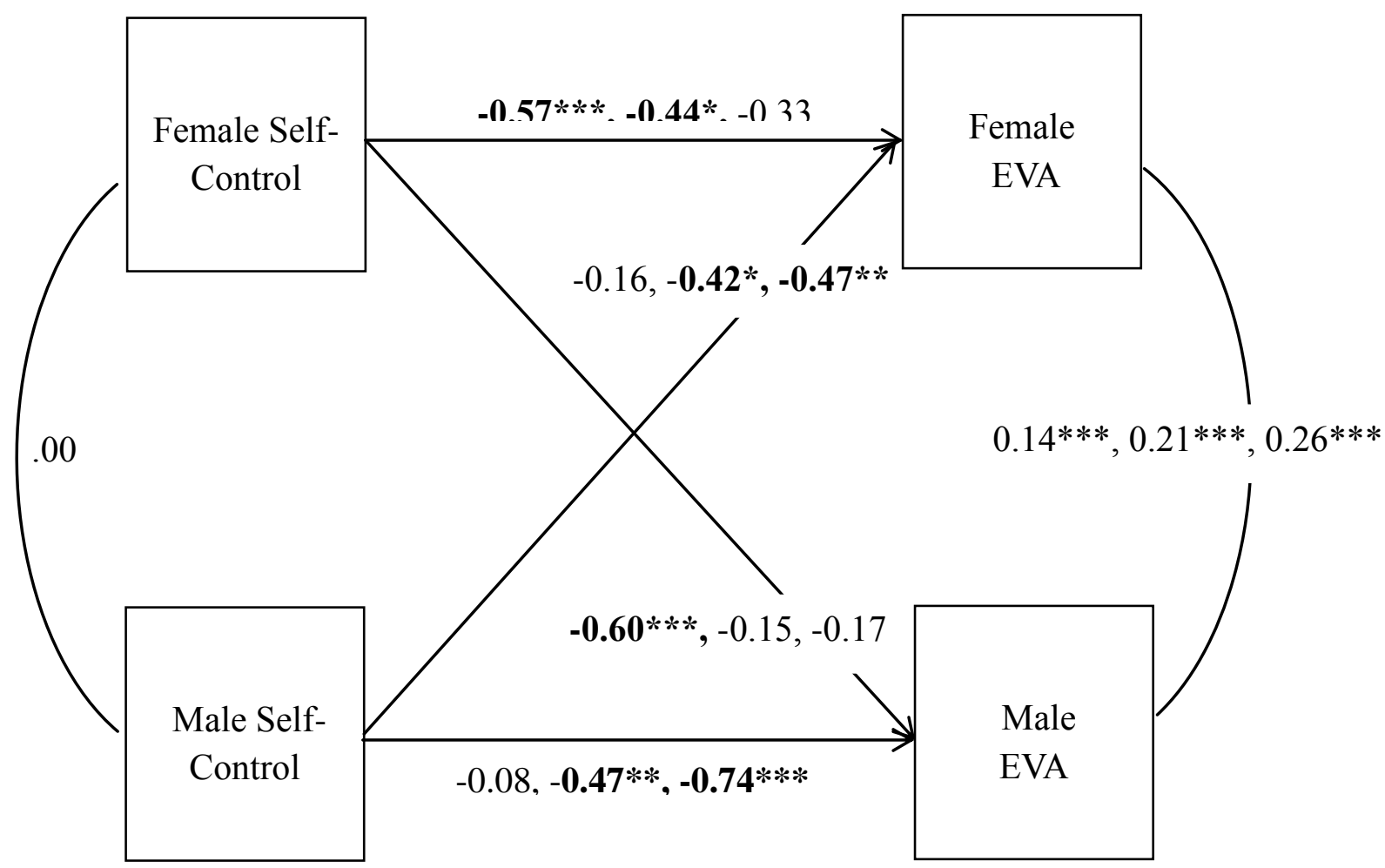

Note. $* \mathrm{p}<.05, * * \mathrm{p}<.01, * * * \mathrm{p}<.001$. Unstandardized coefficients are reported in the order of observed perpetration of EVA, self-reported perpetration of EVA, and self-reported victimization of EVA 


\section{Discussion}

This study extends previous findings on dating aggression by assessing selfcontrol of both partners in a dating relationship to examine EVA perpetration and victimization during conflict within a dyadic framework. We found — consistent with previous research (Finkel et. al, 2009; Archer, Fernández-Fuertes, \& Thanzami, 2010; DeWall et. al, 2011; Denson et. al, 2012; Warnken et. al, 1994; Watkins et al., 2015) that self-control was negatively associated with dating aggression. Importantly, our findings also extend the empirical literature by highlighting the importance of examining EVA during couple conflict within a dyadic framework. Our findings suggest that the association between self-control and EVA is not consistent across methodology, and that the association between self-control and perpetration of EVA is similar to the association between self-control and victimization of EVA.

\section{Self-control associated with EVA}

We hypothesized, as guided by the $\mathrm{I}^{3}$ theory (Finkel, 2013; Finkel, 2007), that there would be a negative association between self-control and EVA. Overall, our findings supported this association. These findings not only confirm theoretical work on the association between self-control and dating aggression, but also extend previous work (which largely focused on physical aggression) to EVA during couple conflict (a subtype of aggression not yet examined). Therefore, the importance of self-control as an 
inhibiting factor extends to interactions between couples as they experience in the moment conflict. Recognizing low self-control as a risk factor for perpetrating EVA during couple conflict is an important step in not only reducing EVA, but also for reducing physical aggression. EVA in marriages (before any physical aggression occurs) is predictive of later physical aggression (Murphy \& O'Leary, 1989). Therefore, intervening to decrease EVA before physical aggression occurs by bolstering self-control is a promising avenue for decreasing later, more extreme forms of aggression. Future research should continue to examine the role of self-control as guided by the $\mathrm{I}^{3}$ theory in predicting multiple forms of dating aggression.

\section{Both self and partner self-control associated with EVA}

We hypothesized, as guided by the dynamic developmental systems perspective (Capaldi et al., 2005), that partner self-control would be associated with EVA. Our hypothesis was confirmed, providing empirical support for the theoretical notion that studying risk factors of both partners is important in understanding EVA in dating relationships.

An example of partner effects can be found in our data that demonstrates that female self-control is negatively associated with male perpetration of observed EVA. These findings suggest that researchers should begin to examine these partner effects in order to understand the mechanisms behind the dyadic interaction. For example, and as our findings suggest, it could be the case that females who have lower levels of self-

control are more likely to perpetrate EVA. This may, in turn, cause their male partners to 
experience more negative emotions during conflict, which causes them to perpetrate retaliatory EVA. Indeed, research shows that when males experience negative emotions (perhaps from being victimized by their partner), they are more likely to aggress (Watkins et al., 2015; Verona \& Curtin, 2006).

The findings from the current study highlight the importance of assessing the complex interplay between dating partners during conflict resolution tasks at the dyadic level. This is particularly important for relationship education where couples need to not just focus on one's own behavior, but also acknowledge that both partners play a role in the perpetration and victimization of EVA. By educating couples on how their own behavior affects their partner's actions as well as how their partner's behavior affects their own actions, individuals may be more confident to make educated decisions such as selecting future dating partners who possess higher self-control. They may also consider engaging in activities (and encouraging their partner to do the same) that bolster selfcontrol in an effort to decrease dating aggression. The current literature is lacking this informative dyadic perspective (e.g., Capaldi et. al, 2012), largely focusing on providing information on the role of an individual's self-control in predicting their own dating aggression, and not taking into account the impact of their partner. Without this dyadic perspective, we cannot draw conclusions regarding the within-dyad bidirectional effects of dating aggression. This is problematic for understanding the mechanisms behind dating aggression, as well as for informing interventions at the couple level. 


\section{Hypotheses' extension across methodologies}

We examined if the association between self-control and EVA would extend across methodologies. We found gender differences using observational methodology that we did not find using self-report. In order to understand these findings, we must first take into account the nature of what survey measures and observational methodology capture.

It is possible that these unique methodologies assess different types of conflict between couples. Indeed, research suggests that both observational and self-report methodology used to assess EVA predicts unique variance within romantic couples (van Dulmen et al., 2012). Observational methodology is context-dependent, such that the EVA is assessed when couples are privately discussing one problem area in their relationship with a common goal in mind to come to an agreement or a compromise. This is different than self-report methodology, which assesses non-context-dependent conflict by simply asking individuals to report on the frequency of EVA "during an argument". This type of self-report methodology has much more variability associated with it in terms of the type of conflict it assesses, and could include one-sided arguments or minor fights in the presence of others. Therefore, it is not limited to context-dependent conflict resolution between couples.

Taking into account the nature of the context-dependent conflict assessed in observational assessment, it is possible to speculate about explanations for the gender differences we found. We found an association between female self-control and observed 
EVA for females. However, we did not find an association between male self-control and observed EVA for males. This might be understood by considering gender-specific conflict styles during conflict resolution. Research shows that men are likely to stonewall (withdrawing from an interaction, shutting off communication) during conflict resolution with their significant other (Gottman, Coan, Carrere, \& Swanson, 1998). Men who stonewall are attempting to end the conflict by not saying anything, and believe that if they remain silent, their partner will stop arguing. It is possible that men are more likely to remain silent in an attempt to stonewall during these context-dependent conflicts, and therefore do not show perpetration of EVA even with low levels of self-control.

Although it is important to examine multiple contexts of conflict, observational methodology much more closely parallels the context of conflict that is assessed during couple's therapy. Additionally, it is more consistent with the dynamic developmental systems perspective, such that one can observe the back and forth interaction between both members of the couple and thus take a truly dyadic perspective. Observing how the association between self-control and EVA functions with this type of methodology is more externally valid compared to survey measures, and thus more informative for interventions and couples therapy. The findings highlight the importance of considering observationally methodology as claims about predictors of EVA seem to differ depending as a function of EVA methodology. 


\section{Does self-control differentially predict EVA perpetration versus EVA victimization?}

We examined if the association between self-control and self-reported perpetration of EVA differed from the association between self-control and self-reported victimization of EVA. We found that generally, the associations did not differ from one another. Although this suggests that both victimization and perpetration have similar predictors, there are likely different explanations for each association. As previously stated, the association between self-control and perpetration of EVA can be understood using the $\mathrm{I}^{3}$ theory, such that individuals who have weaker inhibiting forces are more likely to perpetrate aggression. However, the association between self-control and victimization may require a different explanation.

Self-control theory (Gottfredson \& Hirschi, 1990; Schreck, 1999) suggests that individuals with low levels of self-control are at higher risk for violent victimization. Individuals with low self-control possess certain characteristics that may aggravate other individuals in interpersonal contexts. For example, those with low self-control tend to speak on impulse without thinking, which could aggravate one's partner. As a result, their partner (regardless of their own personal levels of self-control) may perpetrate retaliatory aggression due to experiencing frustration. Additionally, individuals with low self-control lack foresight (Schreck, 1999) and may therefore not think about the consequences of their actions before perpetrating EVA. Without this foresight, these individuals might be more likely to provoke their partner, and thus experience retaliatory aggression. There is a growing body of research that provides support for the association 
between low levels of self-control and aggression victimization (Schreck, Stewart, \& Fisher, 2006; Gover, Kaukinen \& Fox, 2008; Turanovic, Reisig \& Pratt, 2014; Pratt, Turanovic, Fox, \& Wright, 2014). Furthermore, research suggests that individuals with low levels of self-control are also less likely to make lifestyle changes following victimization (Turanovic \& Pratt, 2014; Schreck et al., 2006). This suggests that individuals with low levels of self-control are not only at risk for victimization, but also may be less likely to leave relationships that are characterized by aggression.

Therefore, although perpetration and victimization are highly correlated, and the association between self-control and victimization appears similar to the association between self-control and perpetration, the explanation behind each relationship is unique. For these reasons, we suggest that perpetration and victimization should continue to be examined separately, as the explanations behind their predictors (as well as outcomes) may differ.

\section{Implications for Interventions}

Our research has implications for couple interventions as well. Mainly, couple interventions should focus on both partners, educating each individual about the importance of both their own and their partner's self-control in perpetrating EVA. This focus on educating both members of the couple is critical if we want to decrease dating aggression, a phenomenon that is dyadic in nature. By educating couples on how their own behavior affects their partner's actions as well as how their partner's behavior affects their own actions, we can move towards decreasing dating aggression. 
A number of intervention programs have been created that have attempted to address the problem of dating aggression at the individual level (Barner \& Carney, 2011; see Whitaker, Murphy, Eckhardt, Hodges, \& Cowart, 2013 for review). These intervention programs have been guided by theories focused mainly on changing the attitudes and behaviors of individuals, specifically the perpetrators of severe physical and sexual aggression. Relatedly, despite the fact that dating aggression is dyadic by its very nature, it is rare to find a program that intervenes at the couple level. The majority of the interventions examined in a recent review aimed to change attitudes and beliefs about dating aggression, to improve relationship skills (such as active listening, expressive communication, and problem solving techniques), or some combination of these interventions (Whitaker et. al, 2013).

While previous interventions regarding dating aggression have had some positive results with regard to changing attitudes and promoting positive relationship skills at the individual level, they have largely been unsuccessful (O'Leary \& Slep, 2012). This may be due to the fact that they have neglected the dyadic nature of dating aggression by not examining the characteristics of both partners involved. We advocate for future interventions guided by the dynamic developmental systems perspective that focus on risk factors of both partners.

In particular, research on risk factors such as self-control, which can be strengthened through training (Baumeister, Vohs, \& Tice, 2007; Finkel, 2007; Finkel et al., 2009) can inform future interventions in an innovative way. For example, mindfulness training through practices such as meditation or yoga (Tang et al., 2007; 
Ramadoss \& Bose, 2010; Keng, Smoski, \& Robins, 2011; Friese, Messner, \& Schaffner, 2012) improves self-control. Self-control is considered to be part of executive functions, a part of cognition that is responsible for higher order thinking and goal-directed behavior. These cognitive abilities work together to allow individuals to consciously control their thoughts and actions (Zelazo \& Müller 2010, p. 575). Interventions that focus on executive functions, such as inhibition through bolstered self-control, can be used as preventative interventions to educate dating couples, as well as to inform couples in relationships where high levels of EVA already exists.

It should be noted that these suggested interventions would involve elements similar to couple's therapy where both members of the couple learn skills to modify their dysfunctional behaviors. The success of modifying dysfunctional behaviors through such interventions may differ depending on whether the couples are dating or married. Young adult dating couples differ from married couples on a few dimensions (i.e., length of relationship, level of commitment, age), and these differences could affect the efficacy of the intervention.

For instance, it is possible that because married couples have been together for a longer amount of time as compared to young adult dating couples, their behavioral interactions are more deeply ingrained and therefore more difficult to change. However, married couples who have been together for many years may be more likely to commit to modifying their behaviors in an attempt to improve their relationship. Indeed, research suggests that length of the relationship positively predicts success in couple's therapy, perhaps as an indicator of commitment (Atkins et al., 2005). Young adult dating couples, 
who have not been together as long as married couples, may lack this level of commitment to modifying dysfunctional behaviors. However, their behaviors may be more easily modified as their interactions may not as deeply ingrained as compared to couples who have been married for many years. Relatedly, because young adult dating couples' executive functions are not yet fully developed (De Luca et al., 2003), they may be more likely to benefit from interventions due to their increased potential for plasticity. These inherent differences of young adult dating couples vs. married couples should be taken into account when creating couple intervention programs. Consequently, future research should examine how these interventions might need to be tailored to individual couples depending on the status of their relationship.

In sum, our research advocates for the importance of considering both members

of the dyad and therefore for also teaching skillsets to both partners in order to decrease the likelihood of perpetration and victimization of EVA. Future interventions that work to strengthen self-control of both partners, possibly through the use of mindfulness training, are recommended in order to decrease instances of EVA. Additionally, educating both members of the couple about the dyadic nature of conflict is imperative to decreasing EVA.

\section{Limitations}

While the results of this study have provided the next logical step for investigating dating aggression within couples, we acknowledge that there several limitations to our study. Our participants came from a Midwestern state university, and it 
is not clear whether the results from this study translate to other community or at-risk samples. It is be possible that the association between self-control and EVA is stronger in high risk samples. While dating aggression on a college campus is a serious and prevalent issue, further research should be conducted that draws from a community sample to investigate whether or not the mechanisms between self-control and EVA differ depending on the sample. Neighborhood and community-level risk factors have begun to receive more attention as a risk factor in dating aggression (Capaldi et. al, 2012), and although there are mixed results with regard to larger community contextual factors, it is important to examine these risk factors in future studies in order to better understand how one's environment might impact their behaviors.

Additionally, it is essential to take culture into account for any theoretical work and for investigating whether interventions need to be tailored to specific subpopulations. While this research supports previous theoretical claims, we acknowledge that our sample was largely Caucasian, and therefore our results may not generalize to a more diverse sample. Our sample was not an at-risk population, and therefore may not have been subjected to a variety of stressors to which an at-risk culture may have been exposed. Given that different forms of stress (such as financial stressors or work stressors) are predictive of dating aggression (Capaldi et. al, 2012), we suggest that future research examines at-risk populations and minorities. 


\section{Summary}

In conclusion, the findings from our study extend previous research guided by the

$\mathrm{I}^{3}$ theory and show that the association between self-control and aggression extends to EVA during couple conflict. Additionally, our findings support the theoretical claims made by the dynamic developmental systems perspective, providing further empirical evidence for interactive and dyadic effects within dating couples. Furthermore, it highlights the need to use multiple methodologies to understand how the association between self-control and EVA may differ for males and females depending on methodology. This research helps inform future research by setting a precedent for studying both partners in the dating relationship and using multiple methods of assessment. Perhaps even more importantly, this research can inform future interventions. 


\section{References}

Archer, J., Fernández-Fuertes, A. A., \& Thanzami, V. L. (2010). Does cost-benefit analysis or self-control predict involvement in two forms of aggression?. Aggressive behavior, 36, 292-304.

Atkins, D. C., Berns, S. B., George, W. H., Doss, B. D., Gattis, K., \& Christensen, A.(2005). Prediction of response to treatment in a randomized clinical trial of marital therapy. Journal of Consulting and Clinical Psychology,73(5), 893.

Baker, C. R., \& Stith, S. M. (2008). Factors predicting dating violence perpetration among male and female college students. Journal of Aggression, Maltreatment and Trauma, 17, 227-244

Barner, J. R., \& Carney, M. M. (2011). Interventions for intimate partner violence: A historical review. Journal of Family Violence, 26, 235-244.

Baumeister, R. F., Vohs, K. D., \& Tice, D. M. (2007). The strength model of self-control. Current Directions in Psychological Science, 16, 351-355.

Capaldi, D. M., \& Gorman-Smith, D. (2003). The development of aggression in young male/female couples.

Capaldi, D. M., \& Kim, H. K. (2007). Typological approaches to violence in couples: A critique and alternative conceptual approach. Clinical Psychology Review, 27, 253-265.

Capaldi, D. M., Kim, H. K., \& Shortt, J. W. (2004). Women's involvement in aggression in young adult romantic relationships: A developmental systems model. In M. 
Putallaz \& K. Bierman (Ed.), Aggression, antisocial behavior, and violence among girls (pp. 223-241). New York: Guilford.

Capaldi, D. M., Knoble, N. B., Shortt, J. W., \& Kim, H. K. (2012). A systematic review of risk factors for intimate partner violence. Partner abuse, 3, 231-280.

Capaldi, D. M., Shortt, J. W., \& Crosby, L. (2003). Physical and psychological aggression in at-risk young couples: Stability and change in young adulthood. Merrill-Palmer Quarterly, 49, 1-27.

Capaldi, D. M., Shortt, J. W., \& Kim, H. K. (2005). A life span developmental systems perspective on aggression toward a partner. In W. M. Pinsof \& J. L. Lebow (Eds.), Family psychology: The art of the science (pp. 141-167). Oxford, England: Oxford University Press.

Centers for Disease Control and Prevention, National Center for Injury Prevention and Control (2010a). National Intimate Partner and Sexual Violence Survey: 2010 Summary Report. Retrieved July 17, 2014, from http://www.cdc.gov/violenceprevention/pdf/nisvs_report2010-a.pdf

Centers for Disease Control and Prevention, National Center for Injury Prevention and Control (2010b). National Intimate Partner and Sexual Violence Survey. Retrieved June 11, 2012, from http://www.cdc.gov/ViolencePrevention/pdf/NISVS_FactSheet-a.pdf Cox, M. (1991). Marital and Parent-Child Relationships Study. Unpublished manuscript, University of North Carolina at Chapel Hill. 
De Luca, C. R., Wood, S. J., Anderson, V., Buchanan, J. A., Proffitt, T. M., Mahony, K., \& Pantelis, C. (2003). Normative data from the CANTAB. I: development of executive function over the lifespan. Journal of Clinical and Experimental Neuropsychology, 25, 242-254.

Denson, T. F., DeWall, C. N., \& Finkel, E. J. (2012). Self-control and aggression. Current Directions in Psychological Science, 21, 20-25.

DeWall, C. N., Finkel, E. J., \& Denson, T. F. (2011). Self-Control Inhibits Aggression. Social and Personality Psychology Compass, 5, 458-472.

Finkel, E. J. (2007). Impelling and inhibiting forces in the perpetration of intimate partner violence. Review of General Psychology, 11, 193.

Finkel, E. J., \& Campbell, W. K. (2001). Self-control and accommodation in close relationships: an interdependence analysis. Journal of Personality and Social Psychology, 81, 263

Finkel, E. J., DeWall, C. N., Slotter, E. B., Oaten, M., \& Foshee, V. A. (2009). Selfregulatory failure and intimate partner violence perpetration. Journal of Personality and Social Psychology, 97, 483.

Finkel, E. (2013). The I3 Model: Meta-theory, theory, and evidence. Advances in experimental social psychology, 49, 1.

Friese, M., Messner, C., \& Schaffner, Y. (2012). Mindfulness meditation counteracts self-control depletion. Consciousness and cognition, 21, 1016-1022. 
Grasmick, H. G., Tittle, C. R., Bursik, R. J., \& Arneklev, B. J. (1993). Testing the core empirical implications of Gottfredson and Hirschi's general theory of crime. Journal of Research in Crime and Delinquency, 30, 5-29.

Gottfredson MR, \& Hirschi T (1990) A general theory of crime. Stanford University Press, Stanford,CA

Gottman, J. M., Coan, J., Carrere, S., \& Swanson, C. (1998). Predicting marital happiness and stability from newlywed interactions. Journal of Marriage and the Family, 522.

Gover, A. R., Kaukinen, C., \& Fox, K. A. (2008). The relationship between violence in the family of origin and dating violence among college students. Journal of Interpersonal Violence.

Keng, S. L., Smoski, M. J., \& Robins, C. J. (2011). Effects of mindfulness on psychological health: A review of empirical studies. Clinical psychology review, 31, 1041-1056.

Kenny, D. A. (1996). Models of non-independence in dyadic research. Journal of Social and Personal Relationships, 13, 279-294.

Kenny, D. A., Kashy, D. A., \& Cook, W. L. (2006). Dyadic data analysis. New York: Guilford.

Lawrence, E., Yoon, J., Langer, A., \& Ro, E. (2009). Is psychological aggression as detrimental as physical aggression? The independent effects of psychological aggression on depression and anxiety symptoms. Violence and Victims, 24, 2035. 
Maldonado, R. C., DiLillo, D., \& Hoffman, L. (2015). Can college students use emotion regulation strategies to alter intimate partner aggression-risk behaviors? An examination using $\mathrm{I}^{3}$ theory. Psychology of Violence, 5, 46.

Marsh, N. V., \& Martinovich, W. M. (2006). Executive dysfunction and domestic violence. Brain Injury, 20, 61-66.

Murphy, C., \& O’Leary, K. D. (1989). Psychological aggression predicts physical aggression in early marriage. Journal of Consulting and Clinical Psychology, 57, $579-582$.

O’Leary, K. D., \& Slep, A. M. S. (2012). Prevention of partner violence by focusing on behaviors of both young males and females. Prevention Science, 13, 329-339.

Pratt, T. C., Turanovic, J. J., Fox, K. A., \& Wright, K. A. (2014). Self-control and victimization: A meta-analysis. Criminology, 52, 87-116.

Ramadoss, R., \& Bose, B. K. (2010). Transformative life skills: Pilot study of a yoga model for reduced stress and improving self-control in vulnerable youth. International Journal of Yoga Therapy, 1, 73-78.

Schreck, C. J. (1999). Criminal victimization and low self-control: An extension and test of a general theory of crime. Justice Quarterly, 16, 633-654.

Schreck, C. J., Stewart, E. A., \& Fisher, B. S. (2006). Self-control, victimization, and their influence on risky lifestyles: A longitudinal analysis using panel data. Journal of Quantitative Criminology, 22, 319-340.

Straight, E. S., Harper, F. W., \& Arias, I. (2003). The impact of partner psychological abuse on health behaviors and health status in college women. Journal of 
Interpersonal Violence, 18, 1035-1054.

Taft, C. T., O'Farrell, T. J., Torres, S. E., Panuzio, J., Monson, C. M., Murphy, M., \& Murphy, C. M. (2006). Examining the correlates of psychological aggression among a community sample of couples. Journal of Family Psychology, 20, 581.

Tang, Y. Y., Ma, Y., Wang, J., Fan, Y., Feng, S., Lu, Q., .. \& Posner, M. I. (2007). Short-term meditation training improves attention and self-regulation. Proceedings of the National Academy of Sciences, 104, 17152-17156.

Turanovic, J. J., \& Pratt, T. C. (2014). “Can’t stop, won’t stop”: Self-control, risky lifestyles, and repeat victimization. Journal of quantitative criminology, 30(1), $29-56$.

Turanovic, J. J., Reisig, M. D., \& Pratt, T. C. (2014). Risky Lifestyles, Low Self-control, and Violent Victimization Across Gendered Pathways to Crime. Journal of Quantitative Criminology, 1-24.

van Dulmen, M. H., Mata, A. D., \& Klipfel, K. M. (2012). Enhancing the assessment of verbal aggression through observational methodology. Journal of interpersonal violence, $27,812-823$.

Verona, E., \& Curtin, J. J. (2006). Gender differences in the negative affective priming of aggressive behavior. Emotion, 6, 115 .

Walling, S. M., Meehan, J. C., Marshall, A. D., Holtzworth-Munroe, A., \& Taft, C. T. (2012). Journal of Marital and Family Therapy, 38, 471-485.

Warnken, W. J., Rosenbaum, A., Fletcher, K. E., Hoge, S. K., \& Adelman, S. A. (1994). Head-injured males: A population at risk for relationship aggression?. Violence 
and victims, 9, 153-166.

Watkins, L. E., DiLillo, D., Hoffman, L., \& Templin, J. (2015). Do self-control depletion and negative emotion contribute to intimate partner aggression? A lab-based study. Psychology of Violence, 5(1), 35.

Whitaker, D. J., Murphy, C. M., Eckhardt, C. I., Hodges, A. E., \& Cowart, M. (2013). Effectiveness of primary prevention efforts for intimate partner violence. Partner Abuse, 4, 175-195.

Wolfe, D. A., Scott, K., Reitzel-Jaffe, D., Wekerle, C., Grasley, C., \& Straatman, A. L. (2001). Development and validation of the conflict in adolescent dating relationships inventory. Psychological Assessment, 13, 277.

Zelazo, P. D., \& Müller (2010). Executive function in typical and atypical development. In U. Goswami (Eds.), The Wiley-Blackwell Handbook of Childhood Cognitive Development, Second edition (pp 574-603). Blackwell Publishing Ltd. 


\section{Appendix}

\section{$\mathrm{SC}$}

Directions: Please circle the answer that best applies to you in general.

1. I often act on the spur of the moment without stopping to think.

2. If things I do upset people, it's their problem, not mine.

3. I like to test myself every now and then by doing something a little risky.

4. Sometimes I will take a risk just for the fun of it.

5. I frequently try to avoid projects that I know will be difficult.

6. I sometimes find it exciting to do things for which I might get into trouble.

7. I dislike really hard tasks that stretch my ability to the limit.

8. If I had a choice, I would almost always rather do something physical than mental.

9. I often do whatever brings me pleasure here and now, even at the cost of some distant goal.

10. I almost always feel better when I am on the move than when I am sitting and thinking.

11. Excitement and adventure are more important to me than security.

12. I try to look out for myself first, even if it means making things difficult for other people.

13. I am more concerned with what happens to me in the short run than in the long run.

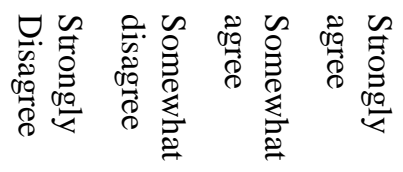

$\begin{array}{llll}1 & 2 & 3 & 4\end{array}$

$1 \quad 2 \quad 3 \quad 4$

$\begin{array}{llll}1 & 2 & 3 & 4\end{array}$

$\begin{array}{llll}1 & 2 & 3 & 4\end{array}$

$\begin{array}{llll}1 & 2 & 3 & 4\end{array}$

$\begin{array}{llll}1 & 2 & 3 & 4\end{array}$

$\begin{array}{llll}1 & 2 & 3 & 4\end{array}$

$\begin{array}{llll}1 & 2 & 3 & 4\end{array}$

$\begin{array}{llll}1 & 2 & 3 & 4\end{array}$

$\begin{array}{llll}1 & 2 & 3 & 4\end{array}$

$\begin{array}{llll}1 & 2 & 3 & 4\end{array}$

$\begin{array}{llll}1 & 2 & 3 & 4\end{array}$

$\begin{array}{llll}1 & 2 & 3 & 4\end{array}$


14. I will try to get things I want even when I know it's causing problems for other people.

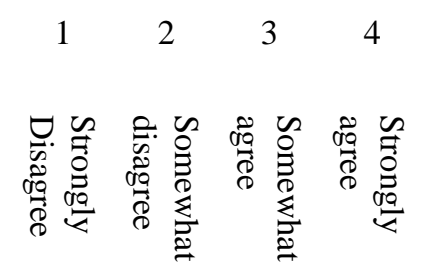

15. When things get complicated, I tend to quit or withdraw.

$1 \quad 2 \quad 3 \quad 4$

16. I like to get out and do things more than I like to read or contemplate ideas. $\begin{array}{lllll}1 & 2 & 3 & 4\end{array}$

17. I'm not very sympathetic to other people when they are having problems. $\begin{array}{lllll}1 & 2 & 3 & 4\end{array}$

18. I seem to have more energy and a greater need for activity than most
people my age.

19. The things in life that are easiest to do bring me the most pleasure. $\quad \begin{array}{lllll}1 & 2 & 3 & 4\end{array}$

20. I don't devote much thought and effort to preparing for the future. $\quad \begin{array}{llll}1 & 2 & 3 & 4\end{array}$

21. I lose my temper pretty easily. $\quad \begin{array}{lllll}1 & 2 & 3 & 4\end{array}$

22. Often, when I am angry at people, I feel more like hurting them than
talking to them about why I am angry.

23. When I'm really angry, other people should stay away from me. $\quad \begin{array}{lllll}1 & 2 & 3 & 4\end{array}$

24. When I have a serious disagreement with someone, it's usually hard for me
to talk calmly about it without getting upset. 
The following questions ask you about things that may have happened to you with your boyfriend/girlfriend while you were having an argument. Check the box that is your best estimate of how often these things have happened with your current boyfriend/girlfriend in the past year. Please remember that all answers are confidential. As a guide use the following scale:

Never: This has never happened in your relationship

Seldom: This has happened only 1-2 times in your relationship

Sometimes: This has happened about 3-5 times in your relationship

Often: This has happened 6 times or more in your relationship

\begin{tabular}{|c|c|c|c|c|c|}
\hline & During a conflict or argument with my boyfriend/girlfriend in the past year: & $\underset{\substack{Z \\
3}}{3}$ & $\frac{2}{\frac{2}{2}}$ & 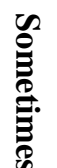 & $\stackrel{?}{\stackrel{9}{g}}$ \\
\hline 1 & \multirow{2}{*}{$\begin{array}{l}\text { I gave reasons for my side of the argument. } \\
\text { He/she gave reasons for his/her side of the argument. }\end{array}$} & 1 & 2 & 3 & 4 \\
\hline & & 1 & 2 & 3 & 4 \\
\hline \multirow[t]{2}{*}{2} & \multirow{2}{*}{$\begin{array}{l}\text { I touched him sexually when he/she didn't want me to. } \\
\text { He/she touched me sexually when I didn't want him/her to. }\end{array}$} & 1 & 2 & 3 & 4 \\
\hline & & 1 & 2 & 3 & 4 \\
\hline \multirow[t]{2}{*}{3} & \multirow{2}{*}{$\begin{array}{l}\text { I tried to turn his/her friends against him/her. } \\
\text { He/she tried to turn my friends against me. }\end{array}$} & 1 & 2 & 3 & 4 \\
\hline & & 1 & 2 & 3 & 4 \\
\hline \multirow[t]{2}{*}{4} & \multirow{2}{*}{$\begin{array}{l}\text { I did something to make him/her feel jealous. } \\
\text { He/she did something to make me feel jealous. }\end{array}$} & 1 & 2 & 3 & 4 \\
\hline & & 1 & 2 & 3 & 4 \\
\hline \multirow[t]{2}{*}{5} & \multirow{2}{*}{$\begin{array}{l}\text { I destroyed or threatened to destroy something he/she valued. } \\
\mathrm{He} / \text { she destroyed or threatened to destroy something I valued. }\end{array}$} & 1 & 2 & 3 & 4 \\
\hline & & 1 & 2 & 3 & 4 \\
\hline \multirow[t]{2}{*}{6} & \multirow{2}{*}{$\begin{array}{l}\text { I told him/her that I was partly to blame. } \\
\mathrm{He} / \text { she told me that he/she was partly to blame. }\end{array}$} & 1 & 2 & 3 & 4 \\
\hline & & 1 & 2 & 3 & 4 \\
\hline \multirow[t]{2}{*}{7} & \multirow{2}{*}{$\begin{array}{l}\text { I brought up something bad that he/she had done in the past. } \\
\text { He/she brought up something bad that I had done in the past. }\end{array}$} & 1 & 2 & 3 & 4 \\
\hline & & 1 & 2 & 3 & 4 \\
\hline \multirow[t]{2}{*}{8} & \multirow{2}{*}{$\begin{array}{l}\text { I threw something at him/her. } \\
\text { He/she threw something at me. }\end{array}$} & 1 & 2 & 3 & 4 \\
\hline & & 1 & 2 & 3 & 4 \\
\hline \multirow[t]{2}{*}{9} & \multirow{2}{*}{$\begin{array}{l}\text { I said things just to make him/her angry. } \\
\text { He/she said things just to make me angry. }\end{array}$} & 1 & 2 & 3 & 4 \\
\hline & & 1 & 2 & 3 & 4 \\
\hline
\end{tabular}




\begin{tabular}{|c|c|c|c|c|c|}
\hline \multirow[t]{3}{*}{10} & \multirow{2}{*}{$\begin{array}{l}\text { I gave reasons why I thought he/she was wrong. } \\
\text { He/she gave reasons why he/she thought I was wrong. }\end{array}$} & 1 & 2 & 3 & 4 \\
\hline & & 1 & 2 & 3 & 4 \\
\hline & During a conflict or argument with my boyfriend/girlfriend in the past year: & 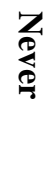 & $\frac{0^{2}}{0}$ & 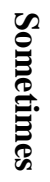 & $\stackrel{\odot}{\stackrel{\odot}{g}}$ \\
\hline \multirow[t]{2}{*}{11} & \multirow{2}{*}{$\begin{array}{l}\text { I agreed that he/she was partly right. } \\
\text { He/she agreed that I was partly right. }\end{array}$} & 1 & 2 & 3 & 4 \\
\hline & & 1 & 2 & 3 & 4 \\
\hline \multirow[t]{2}{*}{12} & \multirow{2}{*}{$\begin{array}{l}\text { I spoke to him/her in a hostile or mean tone of voice. } \\
\text { He/she spoke to me in a hostile or mean tone of voice. }\end{array}$} & 1 & 2 & 3 & 4 \\
\hline & & 1 & 2 & 3 & 4 \\
\hline \multirow[t]{2}{*}{13} & \multirow{2}{*}{$\begin{array}{l}\text { I forced him/her to have sex with me when he/she didn't want to. } \\
\text { He/she forced me to have sex when I didn't want to. }\end{array}$} & 1 & 2 & 3 & 4 \\
\hline & & 1 & 2 & 3 & 4 \\
\hline \multirow[t]{2}{*}{14} & \multirow{2}{*}{$\begin{array}{l}\text { I offered a solution that I thought would make us both happy. } \\
\text { He/she offered a solution that he/she thought would make us both happy. }\end{array}$} & 1 & 2 & 3 & 4 \\
\hline & & 1 & 2 & 3 & 4 \\
\hline \multirow[t]{2}{*}{15} & \multirow{2}{*}{$\begin{array}{l}\text { I threatened him/her in an attempt to have sex with him/her. } \\
\text { He/she threatened me in an attempt to have sex with me. }\end{array}$} & 1 & 2 & 3 & 4 \\
\hline & & 1 & 2 & 3 & 4 \\
\hline \multirow[t]{2}{*}{16} & \multirow{2}{*}{$\begin{array}{l}\text { I put off talking until we calmed down. } \\
\text { He/she put off talking until we calmed down. }\end{array}$} & 1 & 2 & 3 & 4 \\
\hline & & 1 & 2 & 3 & 4 \\
\hline \multirow[t]{2}{*}{17} & \multirow{2}{*}{$\begin{array}{l}\text { I insulted him/her with put-downs. } \\
\text { He/she insulted me with put-downs. }\end{array}$} & 1 & 2 & 3 & 4 \\
\hline & & 1 & 2 & 3 & 4 \\
\hline \multirow[t]{2}{*}{18} & \multirow{2}{*}{$\begin{array}{l}\text { I discussed the issue calmly. } \\
\text { He/she discussed the issue calmly. }\end{array}$} & 1 & 2 & 3 & 4 \\
\hline & & 1 & 2 & 3 & 4 \\
\hline \multirow[t]{2}{*}{19} & \multirow{2}{*}{$\begin{array}{l}\text { I kissed him/her when he/she didn't want me to. } \\
\text { He/she kissed me when I didn't want him/her to. }\end{array}$} & 1 & 2 & 3 & 4 \\
\hline & & 1 & 2 & 3 & 4 \\
\hline \multirow[t]{2}{*}{20} & \multirow{2}{*}{$\begin{array}{l}\text { I said things to his/her friends about him/her to turn them against him/her. } \\
\mathrm{He} / \text { she said things to my friends about me to turn them against me. }\end{array}$} & 1 & 2 & 3 & 4 \\
\hline & & 1 & 2 & 3 & 4 \\
\hline \multirow[t]{2}{*}{21} & \multirow{2}{*}{$\begin{array}{l}\text { I ridiculed or made fun of him/her in front of others. } \\
\mathrm{He} / \text { she ridiculed or made fun of me in front of others. }\end{array}$} & 1 & 2 & 3 & 4 \\
\hline & & 1 & 2 & 3 & 4 \\
\hline \multirow[t]{2}{*}{22} & \multirow{2}{*}{$\begin{array}{l}\text { I told him/her how upset I was. } \\
\text { He/she told me how upset he/she was. }\end{array}$} & 1 & 2 & 3 & 4 \\
\hline & & 1 & 2 & 3 & 4 \\
\hline \multirow[t]{2}{*}{23} & \multirow{2}{*}{$\begin{array}{l}\text { I kept track of who he/she was with and where he/she was. } \\
\text { He/she kept track of who I was with and where I was. }\end{array}$} & 1 & 2 & 3 & 4 \\
\hline & & 1 & 2 & 3 & 4 \\
\hline
\end{tabular}




\begin{tabular}{|c|c|c|c|c|c|}
\hline & During a conflict or argument with my boyfriend/girlfriend in the past year: & $\underset{3}{3}$ & $\frac{\mathscr{\mathscr { Q }}}{\frac{\varrho}{2}}$ & 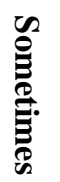 & 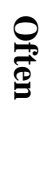 \\
\hline \multirow[t]{2}{*}{24} & \multirow{2}{*}{$\begin{array}{l}\text { I blamed him/her for the problem. } \\
\text { He/she blamed me for the problem. }\end{array}$} & 1 & 2 & 3 & 4 \\
\hline & & 1 & 2 & 3 & 4 \\
\hline \multirow[t]{2}{*}{25} & \multirow{2}{*}{$\begin{array}{l}\text { I kicked, hit or punched him/her. } \\
\text { He/she kicked, hit or punched me. }\end{array}$} & 1 & 2 & 3 & 4 \\
\hline & & 1 & 2 & 3 & 4 \\
\hline \multirow[t]{2}{*}{26} & \multirow{2}{*}{$\begin{array}{l}\text { I left the room to cool down. } \\
\text { He/she left the room to cool down. }\end{array}$} & 1 & 2 & 3 & 4 \\
\hline & & 1 & 2 & 3 & 4 \\
\hline \multirow[t]{2}{*}{27} & \multirow{2}{*}{$\begin{array}{l}\text { I gave in, just to avoid conflict. } \\
\text { He/she gave in, just to avoid conflict. }\end{array}$} & 1 & 2 & 3 & 4 \\
\hline & & 1 & 2 & 3 & 4 \\
\hline \multirow[t]{2}{*}{28} & \multirow{2}{*}{$\begin{array}{l}\text { I accused him/her of flirting with another girl/boy. } \\
\text { He/she accused me of flirting with another girl/boy. }\end{array}$} & 1 & 2 & 3 & 4 \\
\hline & & 1 & 2 & 3 & 4 \\
\hline \multirow[t]{2}{*}{29} & \multirow{2}{*}{$\begin{array}{l}\text { I deliberately tried to frighten him/her. } \\
\text { He/she deliberately tried to frighten me. }\end{array}$} & 1 & 2 & 3 & 4 \\
\hline & & 1 & 2 & 3 & 4 \\
\hline \multirow[t]{2}{*}{30} & \multirow{2}{*}{$\begin{array}{l}\text { I slapped him/her or pulled his/her hair. } \\
\text { He/she slapped me or pulled my hair. }\end{array}$} & 1 & 2 & 3 & 4 \\
\hline & & 1 & 2 & 3 & 4 \\
\hline \multirow[t]{2}{*}{31} & \multirow{2}{*}{$\begin{array}{l}\text { I threatened to hurt him/her. } \\
\text { He/she threatened to hurt me. }\end{array}$} & 1 & 2 & 3 & 4 \\
\hline & & 1 & 2 & 3 & 4 \\
\hline \multirow[t]{2}{*}{32} & \multirow{2}{*}{$\begin{array}{l}\text { I threatened to end the relationship. } \\
\text { He/she threatened to end the relationship. }\end{array}$} & 1 & 2 & 3 & 4 \\
\hline & & 1 & 2 & 3 & 4 \\
\hline \multirow[t]{2}{*}{33} & \multirow{2}{*}{$\begin{array}{l}\text { I threatened to hit him/her or throw something at him/her. } \\
\mathrm{He} / \text { she threatened to hit me or throw something at me. }\end{array}$} & 1 & 2 & 3 & 4 \\
\hline & & 1 & 2 & 3 & 4 \\
\hline \multirow[t]{2}{*}{34} & \multirow{2}{*}{$\begin{array}{l}\text { I pushed, shoved or shook him/her. } \\
\text { He/she pushed, shoved or shook me. }\end{array}$} & 1 & 2 & 3 & 4 \\
\hline & & 1 & 2 & 3 & 4 \\
\hline \multirow[t]{2}{*}{35} & \multirow{2}{*}{$\begin{array}{l}\text { I spread rumors about him/her. } \\
\text { He/she spread rumors about me. }\end{array}$} & 1 & 2 & 3 & 4 \\
\hline & & 1 & 2 & 3 & 4 \\
\hline
\end{tabular}




\section{PIC}

Directions: Listed below are some things which can cause problems for dating couples. Please CIRCLE the number that shows how much each of the following areas is a problem in your current romantic relationship. Use the blanks in numbers $30 \& 31$ to list problem areas not already mentioned. Your partner will fill out this same sheet, and you will both see each other's sheets in the next part of the session.

\begin{tabular}{|c|c|c|c|c|c|c|c|c|c|c|c|}
\hline & & \multicolumn{9}{|c|}{ Not a problem } & $\begin{array}{l}\text { Is a } \\
\text { serious } \\
\text { problem }\end{array}$ \\
\hline 1. & Promising to do something, but not doing it. & 1 & 2 & 3 & 4 & 5 & 6 & 7 & 8 & 9 & 10 \\
\hline 2. & Avoiding talking about difficult issues. & 1 & 2 & 3 & 4 & 5 & 6 & 7 & 8 & 9 & 10 \\
\hline 3. & Deciding where to go on dates. & 1 & 2 & 3 & 4 & 5 & 6 & 7 & 8 & 9 & 10 \\
\hline 4. & Not doing fair share of household tasks. & 1 & 2 & 3 & 4 & 5 & 6 & 7 & 8 & 9 & 10 \\
\hline 5. & Jealousy from talking to another male/female. & 1 & 2 & 3 & 4 & 5 & 6 & 7 & 8 & 9 & 10 \\
\hline 6. & Expecting to spend too much time together. & 1 & 2 & 3 & 4 & 5 & 6 & 7 & 8 & 9 & 10 \\
\hline 7. & Never enough money to do things on dates. & 1 & 2 & 3 & 4 & 5 & 6 & 7 & 8 & 9 & 10 \\
\hline 8. & Sex/contraception issues. & 1 & 2 & 3 & 4 & 5 & 6 & 7 & 8 & 9 & 10 \\
\hline 9. & Expecting each other to spend all free time together. & 1 & 2 & 3 & 4 & 5 & 6 & 7 & 8 & 9 & 10 \\
\hline 10. & Being put down in front of others. & 1 & 2 & 3 & 4 & 5 & 6 & 7 & 8 & 9 & 10 \\
\hline 11. & How often you go on dates. & 1 & 2 & 3 & 4 & 5 & 6 & 7 & 8 & 9 & 10 \\
\hline 12. & Not having shared hobbies/interests. & 1 & 2 & 3 & 4 & 5 & 6 & 7 & 8 & 9 & 10 \\
\hline 13. & Flirted with other males/females. & 1 & 2 & 3 & 4 & 5 & 6 & 7 & 8 & 9 & 10 \\
\hline 14. & Not spending enough time together. & 1 & 2 & 3 & 4 & 5 & 6 & 7 & 8 & 9 & 10 \\
\hline 15. & Not having a job. & 1 & 2 & 3 & 4 & 5 & 6 & 7 & 8 & 9 & 10 \\
\hline 16. & Not liking use of alcohol/cigarettes/marijuana/drugs. & 1 & 2 & 3 & 4 & 5 & 6 & 7 & 8 & 9 & 10 \\
\hline 17. & Not feeling able to be yourself around each other. & 1 & 2 & 3 & 4 & 5 & 6 & 7 & 8 & 9 & 10 \\
\hline 18. & Difficulty talking/knowing what to talk about. & 1 & 2 & 3 & 4 & 5 & 6 & 7 & 8 & 9 & 10 \\
\hline 19. & Deciding whether to go out as a couple or with friends. & 1 & 2 & 3 & 4 & 5 & 6 & 7 & 8 & 9 & 10 \\
\hline 20. & Feeling need to drop own interests and do theirs. & 1 & 2 & 3 & 4 & 5 & 6 & 7 & 8 & 9 & 10 \\
\hline 21. & Not washing self/taking care of hair/clothes (hygiene). & 1 & 2 & 3 & 4 & 5 & 6 & 7 & 8 & 9 & 10 \\
\hline 22. & Not liking his/her attitudes or behaviors. & 1 & 2 & 3 & 4 & 5 & 6 & 7 & 8 & 9 & 10 \\
\hline 23. & Not calling when said would call. & 1 & 2 & 3 & 4 & 5 & 6 & 7 & 8 & 9 & 10 \\
\hline 24. & Not having a car/ transportation for dates. & 1 & 2 & 3 & 4 & 5 & 6 & 7 & 8 & 9 & 10 \\
\hline 25. & Who should pay for dates. & 1 & 2 & 3 & 4 & 5 & 6 & 7 & 8 & 9 & 10 \\
\hline 26. & Not liking some of his/her friends. & 1 & 2 & 3 & 4 & 5 & 6 & 7 & 8 & 9 & 10 \\
\hline 27. & Religious differences & 1 & 2 & 3 & 4 & 5 & 6 & 7 & 8 & 9 & 10 \\
\hline 28. & Parents do not like partner. & 1 & 2 & 3 & 4 & 5 & 6 & 7 & 8 & 9 & 10 \\
\hline 29. & Ethic/Moral differences & 1 & 2 & 3 & 4 & 5 & 6 & 7 & 8 & 9 & 10 \\
\hline 30. & Other: & 1 & 2 & 3 & 4 & 5 & 6 & 7 & 8 & 9 & 10 \\
\hline 31. & Other : & 1 & 2 & 3 & 4 & 5 & 6 & 7 & 8 & 9 & 10 \\
\hline
\end{tabular}




\section{OBSERVATION SCRIPT:}

Researcher 2: Ask the couple the couple to leave Room 352 so you can record the identifying information on the DVD.

Researcher 1: Start video-taping by pressing "record" on DVD player and waiting approximately 13 seconds for it to start recording. When the timer on the DVD player starts hit " $S$ " on the computer keyboard to start.

Researcher 2: Enter Room 352 to record information (TARR, date, couple number, researchers' names) and then ask the couple to come in and have a seat. Take in Relationship Observation Sheets, clipboard, and pen.

\section{MAKE SURE COUPLE IS AWARE OF MICROPHONE $\odot$}

\section{PART I DIRECTIONS:}

"We're now going to videotape the two of you discussing something in your relationship that you currently think is a problem or that you disagree about. First I'm going to give you the list of possible problem areas that each of you has already filled out. Together, I want you to decide what you think is the biggest problem area in your relationship. It may or may not be something on the list, but these should help you think about what it is. This may or may not be something that you have argued about a lot, but it should be the main thing that the two of you disagree about.

All that we want you to do for the first part is to look at your lists together and decide what you think is the biggest problem area in your relationship. We don't need you to discuss each item on the work sheet; we only need you to agree on the problem area you disagree on the most. Once you have agreed on a problem area to discuss, please tell me and then we will start the second part. Take a minute or two now to decide and I'll be back in to check on you." [Hand the couple their Relationship Observation forms. Leave room.]

Top problem must be a problem or disagreement between them in their relationship.

If the couple has trouble knowing what to discuss, the interviewer should talk with them to help them arrive at a reasonable discussion topic. (See problem shooting).

If the couple insists that they have no disagreements, then get them to talk about the area that they listed as the major problem area on their problem inventories.

Return to room:

After the couple has decided on the problem (and you have confirmed that the problem is appropriate for the second episode) take away the problem inventories and proceed to Part II.

$B E$ sure you understand why this is a problem for this couple. 


\section{PART II DIRECTIONS:}

"Now we want you to discuss the problem area of [from earlier discussion]. You may have talked about this before. Still, we want you to talk about the important issues in your disagreement as you both see them, and try to solve the problem in a way that you both can agree on. You should talk only about at this time. You shouldn't discuss other problems. So first each of you should tell the other what your feelings are about the problem you chose and then you should try to reach an agreement that you are both happy with. Do you have any questions? -- Now, so that we are sure that our directions are clear, would one you tell me what you understand the directions to be. [Explain again if necessary] Take about 10 minutes. I'll let you know when the 10 minutes is up."

- $\quad$ Take both Problem Lists with you.

- Hand the participant the sheet with the instructions and their problem area hand written in the area indicated.

- Be sure they understand they need to come to a resolution of the problem.

\section{[Only if the couple asks if they can come get you when they are through, say:]}

"We want you to try to use the whole 10 minutes, so if you feel that you've finished, see if there's anything else that you need to say and wait for us to come in."

Researcher 2 leaves room and shuts the door.

Researcher 1 in control room should begin stopwatch to time 10 minutes.

After 10 minutes, if the couple is still talking:

- Researcher 2 should stick his/her head in after knocking and say:

"Try to wrap up your discussion in the next 2 or 3 minutes."

Researcher 1 should pause the stopwatch while the Researcher 2 pops in.

Stop the discussion after a total of 13 minutes has passed if the couple does not stop before. If the couple is still actively discussing at 13 minutes, you can say:

"Take just 30 seconds to wrap-up."

\section{PART III:}

Researcher 2: Take in Relationship Observation sheets again, with clipboard.

"Here are the lists of possible problem areas that you filled out earlier. I want you to use your lists to decide on the topics you agree on the most in your relationship or those that you disagree on the least. You'll need to talk about this together and 
come to an agreement on what you think are the topics you agree on the most. Take about 4 minutes. I'll come and let you know when the 4 minutes is up. To be sure that you understand the directions, can one of you please repeat them."

ONLY If the couple asks if they can come get you when they are through, say:

"We want you to try to use the whole 4 minutes, so if you feel that you've finished, see if there's anything else that you need to say and wait for us to come in."

Researcher 2 leaves room.

Researcher 1 in control room starts stopwatch to time for 4 minutes.

After 4 minutes, if the couple is still talking, the interviewer should stick his/her head in after knocking and say: (Researcher 1 pause stopwatch).

"Try to wrap up your discussion in the next minute."

Stop the discussion after a total of 5 minutes has passed if the couple does not stop before. If the couple is still actively discussing at 5 minutes, you can say:

"Take just 30 seconds to wrap-up."

\section{PART IV:}

"There is one final task that we would like the two of you to complete. We want you to pretend that you have won a radio contest. The grand prize is an all-expenses paid 3-day weekend. Your job is to plan together what the two of you would do. Remember, you can do anything you want, go anywhere you want, and you have all the money you need. We want you to plan the whole three days together. You will have ten minutes to complete this task. To be sure that you understand the task, can one of you please repeat the instructions?" [Clarify the instructions if the couple is wrong.]

SET CLIPBOARD ON TABLE - DO NOT HAND IT TO ONE OF THE PARTTICIPANTS.

ONLY If the couple asks if they can come get you when they are through, say:

"We want you to try to use the whole 10 minutes, so if you feel that you've finished, see if there's anything else that you need to say and wait for us to come in."

Researcher 2 leaves room.

Researcher 1 starts stopwatch to time for 10 minutes.

After 10 minutes, if the couple is still talking, the interviewer should stick his/her head in after knocking and say: (Researcher 1 pauses the stopwatch).

"Try to wrap up your discussion in the next minute."

Stop the discussion after a total of 11 minutes has passed if the couple does not stop before. If the couple is still actively discussing at 11 minutes, you can say:

"Take just 30 seconds to wrap-up." 
Conclusion:

- Research Assistant 1 in control room should stop videotaping and double check that the tape is recorded appropriately.

When the videotaping is over, say something like:

"Okay, I've finished videotaping. Thank you. I want to check the tape by looking at the last seconds of it to make sure that it recorded you. Feel free to take a break as we did before and I'll make sure everything is okay. 


\section{Did something to make partner jealous:}

The individual deliberately behaves in a way (including verbal comments) that is meant to produce mental uneasiness from (a) suspicion or (b) fear of rivalry or (c) unfaithfulness in the opposite individual during the assessment. Coding of this behavior should focus on the individual's intent perceived by coder.

Examples:

"Well if you think I am so awful, I am going to go hang out with Bob."

"Oh you think I am ugly and weak? That is not what Jill thinks ."

Never. The individual does not demonstrate or mention any action or behavior done deliberately to cause fear of unfaithfulness in the opposite individual during the assessment.

Seldom. The individual demonstrates or mentions an action or behavior done deliberately to cause fear of unfaithfulness in the opposite individual a few times (1-2 times) during the assessment.

Sometimes. The individual demonstrates or mentions any action or behavior done deliberately to cause fear of unfaithfulness in the opposite individual multiple times during the assessment.

Often. The individual frequently demonstrates or mentions any action or behavior done deliberately to cause fear of unfaithfulness in the opposite individual in that it dominates the conversation during the assessment. 


\section{$\underline{\text { Told partner that he/she (participant) was partly to blame }}$}

The individual is directly or indirectly accepting, acknowledging or taking responsibility, that some of their own behaviors or actions have lead either the discussed problem or any other problem brought up during the assessment.

Examples:

"I will admit I make you mad that causes you to yell at me."

"I take responsibility for paying the credit card bills late, but you are the one who charges everything."

Never. The individual does not directly or indirectly accept, acknowledge or take responsibility that his/her own behaviors or actions lead to a problem.

Seldom. The individual has a few (1-2 times) instances where he/she directly or indirectly accepts, acknowledges or takes responsibility that his/her own behaviors or actions lead to a problem.

Sometimes. The individual has multiple instances where he/she directly or indirectly accepts, acknowledges or takes responsibility that his/her own behaviors or actions lead to a problem.

Often. The individual has frequent instances where he/she directly or indirectly accepts, acknowledges or takes responsibility that his/her own behaviors or actions lead to a problem in that it dominates the conversation. 


\section{Brought up something bad that partner did in past:}

In an accusatory tone of voice, the individual mentions a specific behavioral act of their partner that occurred previous to the assessment. The individual who brought up the specific behavioral act views or values the specific behavioral act as negative.

Examples:

[In an accusatory voice] "Remember that time you were over at Kevin's and you went to the basement with Jennifer? ."

[In an accusatory voice] "Remember that day in June when you invaded my privacy by looking through my text messages?"

Never. The individual does not mention a specific behavioral act of their partner that occurred previous to the assessment.

Seldom. In an accusatory tone of voice, the individual mentions specific behavioral acts of their partner that occurred a few times (1-2 times) previous to the assessment.

Sometimes. In an accusatory tone of voice, the individual mentions specific behavioral acts of their partner that occurred multiple times previous to the assessment.

Often. In an accusatory tone of voice, the individual frequently mentions several specific behavioral acts of their partner that occurred previous to the assessment in that it dominates the conversation. 


\section{Said something to make partner angry}

The individual utters words or phrases with the intent to make their partner feel wronged, outraged, frustrated, or irritated. Coding of this behavior should focus on the individual's intent perceived by coder. The decision to code this item may be partially based on the reaction or response of the other individual.

Examples:

"Well I don't know if I want to be in this relationship anymore."

"Nothing is ever your fault, right?"

The decision to code this item may be partially based on the reaction or response of the other individual. For example:

Individual: "Your mom is psycho!"

If the other individual responds with, "Yes, my mom is psycho." Then this is not coded as said something to make partner angry.

If the other individual responds with, "What the hell are you talking about?" Then this is coded as said something to make partner angry.

Never. The individual has no instances of uttering words or phrases with the intent to make their partner feel wronged, outraged, frustrated or irritated.

Seldom. The individual has a few (1-2 times) instances of uttering words or phrases with the intent to make their partner feel wronged, outraged, frustrated or irritated.

Sometimes. The individual has multiple instances of uttering words or phrases with the intent to make their partner feel wronged, outraged, frustrated or irritated.

Often. The individual has frequent instances of uttering words or phrases with the intent to make their partner feel wronged, outraged, frustrated or irritated in which it dominates the conversation. 


\section{Insulted partner with put-down}

The individual says something with the intent to hurt, offend or demean his/her partner. The individual says something that appears to diminish what his/her partner is saying. The individual is placing more value on what he/she is saying.

The something that is said is directly about the partner.

Examples:

"You are an idiot."

"Why are you so dumb?"

"Whatever!"

Never. The individual neither says something to hurt, offend or demean his/her partner nor says something to diminish what his/her partner is saying.

Seldom. The individual has a few (1-2 times) instances of saying something to hurt, offend or demean his/her partner or says something to diminish what his/her partner is saying.

Sometimes. The individual has multiple instances of saying something to hurt, offend or demean his/her partner or says something to diminish what his/her partner is saying.

Often. The individual has frequent instances of saying something to hurt, offend or demean his/her partner or says something to diminish what his/her partner is saying in that it dominates the conversation. 


\section{Blamed partner for problem}

The individual accuses his/her partner for being responsible or at fault for the discussed problem. Responsibility or fault of the problem includes the partner's behaviors, actions or thoughts.

Examples:

"It is all your fault that we can't decide where we are going to eat."

"We don't have any money because you maxed out our credit cards, and we can't pay them off."

"There is nothing wrong with my friends. They are find, you are the problem."

Never. The individual does not accuse his/her partner for being responsible or at fault for a problem.

Seldom. The individual has a few (1-2 times) instances of accusing his/her partner for being responsible or at fault for a problem.

Sometimes. The individual has multiple instances of accusing his/her partner for being responsible or at fault for a problem.

Often. The individual has frequent instances of accusing his/her partner for being responsible or at fault for a problem in which it dominates the conversation. 


\section{Accused partner of flirting with another person:}

In an accusatory tone of voice, the individual accuses their partner of talking or behaving amorously toward another person one or more previous occasions.

Examples:

[In an accusatory voice] "You were talking with her on IM for two hours"

[In an accusatory voice] "You stroked his arm the whole time you two were talking."

Never. The individual does not accuse their partner of talking or behaving amorously toward another person on one or more previous occasions.

Seldom. In an accusatory tone of voice, the individual accuses their partner of talking or behaving amorously toward another person on one or more previous occasions a few times (1-2 times).

Sometimes. In an accusatory tone of voice, the individual accuses their partner of talking or behaving amorously toward another person on one or more previous occasions multiple times.

Often. In an accusatory tone of voice, the individual frequently accuses their partner of talking or behaving amorously toward another person on one or more previous occasions in that it dominates the conversation. 


\section{Couple}

Sex

Coder

Date Coded

\begin{tabular}{|l|c|c|c|c|}
\hline BEHAVIOR & Never & Seldom & Sometimes & Often \\
\hline Did something to make partner jealous & 1 & 2 & 3 & 4 \\
\hline Told partner that he/she (participant) was partly to blame & 1 & 2 & 3 & 4 \\
\hline Brought up something bad that partner did in past & 1 & 2 & 3 & 4 \\
\hline Said something to make partner angry & 1 & 2 & 3 & 4 \\
\hline Insulted partner with put-down & 1 & 2 & 3 & 4 \\
\hline Blamed partner for problem & 1 & 2 & 3 & 4 \\
\hline Accused partner of flirting with another person & 1 & 2 & 3 & 4 \\
\hline
\end{tabular}




\section{Consent Form Participant \\ CONSENT FORM - Participant \\ Transitions to Adulthood and Romantic Relationships}

We want to do research on romantic relationships and transitions into adulthood. We want to do this because we would like to learn about relationships with partners (boyfriend/girlfriend/spouse) and their impact on different areas of young adulthood development. We would like you to take part in this project. If you decide to do this, you will first fill out a packet of questionnaires. Then, you will be asked to answer some questions individually with a research assistant, which will be tape-recorded. We also would like to videotape you and your partner together with the consent of both of you. You will receive a copy of this videotape in DVD format. Today's visit will take approximately two and a half to three hours. You will receive 6 research credits for your Introduction to Psychology course. We would also like you participate in a two-week daily web-based assessment that will last approximately 5-10 minutes each day. For your participation in this phase, you will receive another 6 research credits for completion of at least $75 \%$ of these daily assessments (or 10 of 14 daily assessments). We are also asking for your permission to recontact you in approximately three and six months to do two final followup web-based assessments. These assessments each should last approximately 2025 minutes. You will be compensated $\$ 10$ each time for your participation in both of these phases after completion of the web-based assessment.

All of the information in these sessions will be kept confidential. Each participant will be assigned an ID number to insure confidentiality, and neither you nor your partner's name will ever appear on documents or publications issued from this project. To help us protect your privacy, we have obtained a Certificate of Confidentiality from the National Institutes of Health. With this Certificate, the researchers cannot be forced to disclose information that may identify you, even by a court subpoena, in any federal, state, or local civil, criminal, administrative, legislative, or other proceedings. The researchers will use the Certificate to resist any demands for information that would identify you, except as explained below.

The Certificate cannot be used to resist a demand for information from personnel of the United State Government that is used for auditing or evaluation of federally funded projects or for information that must be disclosed in order to meet the requirements of the federal Food and Drug Administration (FDA).

You should understand that a Certificate of Confidentiality does not prevent you or a member of your family from voluntarily releasing information about yourself or your involvement in this research. If an insurer, employer or other person obtains your written 
consent to receive such information, then the researchers may not use the Certificate to withhold that information.

The Certificate of Confidentiality does not prevent the researchers from disclosing voluntarily, without your consent, if we learn that you intend to harm yourself or someone else.

You may keep this letter and you will be asked to sign the attached consent form. If you decide to take part in this project, you will be helping further the understanding of romantic relationships in early adulthood. You participation is voluntary. Taking part in this project is entirely up to you, and no one will hold it against you if you decide not to do it. If you do take part, you may stop at any time. Feel free to ask any questions you may have prior to or during your participation.

If you want to know more about this research project, please call me at (330) 6722504. The project has been approved by Kent State University. If you have questions about Kent State University's rules for research, please call Dr. Peter C. Tandy, Acting Vice President and Dean, Division of Research and Graduate Studies (Tel. 330.672.2704).

Sincerely,

Manfred van Dulmen, Ph.D.

Principal Investigator

Assistant Professor

Department of Psychology 


\section{Consent Form Partner}

\section{CONSENT FORM - Partner \\ Consent Form: Transitions to Adulthood and Romantic Relationships}

We want to do research on romantic relationships and transitions into adulthood. We want to do this because we would like to learn about relationships with partners (boyfriend/girlfriend/spouse) and their impact on different areas of young adulthood development. We would like you to take part in this project. If you decide to do this, you will first fill out a packet of questionnaires. Then, you will be asked to answer some questions individually with a research assistant, which will be tape-recorded. We also would like to videotape you and your partner together with the consent of both of you. You will receive a copy of the videotape in DVD format. Today's visit will take approximately two and a half to three hours. You will receive \$25 for your participation.

All of the information in these sessions will be kept confidential. Each participant will be assigned an ID number to insure confidentiality, and neither you nor your partner's name will ever appear on documents or publications issued from this project. To help us protect your privacy, we have obtained a Certificate of Confidentiality from the National Institutes of Health. With this Certificate, the researchers cannot be forced to disclose information that may identify you, even by a court subpoena, in any federal, state, or local civil, criminal, administrative, legislative, or other proceedings. The researchers will use the Certificate to resist any demands for information that would identify you, except as explained below.

The Certificate cannot be used to resist a demand for information from personnel of the United State Government that is used for auditing or evaluation of federally funded projects or for information that must be disclosed in order to meet the requirements of the federal Food and Drug Administration (FDA).

You should understand that a Certificate of Confidentiality does not prevent you or a member of your family from voluntarily releasing information about yourself or your involvement in this research. If an insurer, employer or other person obtains your written consent to receive such information, then the researchers may not use the Certificate to withhold that information.

The Certificate of Confidentiality does not prevent the researchers from disclosing voluntarily, without your consent, if we learn that you intend to harm yourself or someone else.

You may keep this letter and you will be asked to sign the attached consent form. If you decide to take part in this project, you will be helping further the understanding of romantic relationships in early adulthood. You participation is voluntary. Taking part in this project is entirely up to you, and no one will hold it against you if you decide not to 
do it. If you do take part, you may stop at any time. Feel free to ask any questions you may have prior to or during your participation.

If you want to know more about this research project, please call me at (330) 6722504. The project has been approved by Kent State University. If you have questions about Kent State University's rules for research, please call Dr. Peter C. Tandy, Acting Vice President and Dean, Division of Research and Graduate Studies (Tel. 330.672.2704).

Sincerely,

Manfred van Dulmen, Ph.D.

Principal Investigator

Assistant Professor

Department of Psychology 


\section{AUDIO CONSENT FORM}

Transitions to Adulthood and Romantic Relationships

I agree to audio taping

at

on
Signature
Date

I have been told that I have the right to hear the audio tapes before they are used. I have decided that I:

want to hear the tapes

do not want to hear the tapes

Sign now below if you do not want to hear the tapes. If you want to hear the tapes, you will be asked to sign after hearing them.

Manfred van Dulmen and other researchers approved by Kent State University may / may not use the tapes made of me. The original tapes or copies may be used for: meetings

this research project teacher education presentation at professional 


\section{VIDEOTAPE CONSENT FORM}

Transitions into Adulthood and Romantic Relationships

I agree to video taping

at

on

Signature Date

I have been told that I have the right to see the video tapes before they are used. I have decided that I:

want to see the tapes

do not want to see the tapes

Sign now below if you do not want to see the tapes. If you want to see the tapes, you will be asked to sign after viewing them.

Manfred van Dulmen and other researchers approved by Kent State University may / may not use the tapes made of me. The original tapes or copies may be used for: meetings

this research project teacher education presentation at professional

Date 